Linha D'Água (Online), São Paulo, v. 31, n. 1, p. 145-170, jan.-abril 2018

\title{
A IDIOMATICIDADE E A FORMULAICIDADE NO DISCURSO ESCRITO EM PORTUGUÊS PRODUZIDO POR ALUNOS UNIVERSITÁRIOS MOÇAMBICANOS
}

\author{
IDIOMATICITY AND FORMULAICITY IN WRITTEN DISCOURSE IN \\ PORTUGUESE PRODUCED BY MOZAMBIQUE UNIVERSITY STUDENTS
}

\author{
Fulieta Machimuassana Langa* \\ Universidade Eduardo Mondlane, Maputo, Moçambique
}

\begin{abstract}
Resumo: A observação de textos redigidos em Português por alunos universitários moçambicanos revela dificuldades de escrita que vão para além do domínio das regras da gramática. As línguas maternas da maioria destes alunos são de raíz Bantu e utilizadas, sobretudo, em ambientes restritos ou familiares. Diferentemente das línguas bantu, o Português, língua segunda da maioria desses alunos, goza do estatuto de língua oficial, do ensino, da administração pública, do contacto com o mundo, sendo também a língua que confere prestígio social em Moçambique. Este quadro propicia transferências linguístico-discursivas, retóricas, culturais e idiomáticas que se manifestam numa variedade de formas de expressão peculiares às línguas e culturas em contacto, na comunicação oral ou escrita, e para o caso da presente pesquisa, enfaticamente na escrita. Neste artigo exploramos até que ponto estes alunos desenvolvem a fluência e a proficiência na língua-alvo, através do modo como organizam as unidades linguístico-discursivas para expressarem a sua visão do mundo, no contexto interlingue e intercultural em que vivem. Selecionamos trechos de 4 composiç,ões por eles produzidas e fizemos incidir a análise na forma como acomodam aspectos da idiomaticidade e da formulaicidade em textos do género opinativo e no âmbito da tipologia argumentativa.
\end{abstract}

Palavras-chave: Fluência e proficiência; Estrutura retórica; Idiomaticidade; Visão do mundo; Competência discursiva.

\begin{abstract}
The observation of texts written in Portuguese by Mozambican university students reveals writing difficulties that goes beyond the realm of knowledge of grammatical rules. The mother tongues of most of these students are of Bantu origin and used mainly in restricted or familiar contexts. Unlike Bantu languages, Portuguese, the second language to most of these students, eniovs the status of official language, of teaching, of public administration, of contact with the world, being the language, which confers social prestige in Mozambique. This framework fosters linguistic, discursive, rhetorical, cultural and idiomatic transfers that manifest themselves in a variety of forms of expression peculiar to the languages and cultures in contact, in oral or written communication, and for the present study, emphatically in writing. In this article, we explore the extent to which these students develop fluency and proficiency in the target language through the way they organize linguistic and discursive units to express their world view in the interlingual and intercultural context in which they live. Thus, we selected pieces of discourse from 4 compositions written by them
\end{abstract}

* Professora doutora da Faculdade de Letras e Ciências Sociais da Universidade Eduardo Mondlane - UEM, Maputo, Moçambique; julieta.langa@uem.mz, julietlangs.j@gmail.com 
Linha D'Água (Online), São Paulo, v. 31, n. 1, p. 145-170, jan.-abril 2018

and focus the analysis on how they accommodate aspects of idiomaticity and formulaicity in texts of the opinion genre and within argumentative typology.

Keywords: Fluency and proficiency; Rhetorical structure; Idiomaticity; Worldview; Discourse competence.

\section{Introdução'}

A análise do discurso escrito em Português por estudantes universitários moçambicanos tem de ser feita tendo em conta que a maioria da população moçambicana, assim como dos estudantes universitários tem o Português como língua segunda (L2) e como maternas (L1), línguas moçambicanas de raíz bantu. Embora seja visível, nas grandes cidades, o aumento do número de pessoas cuja socialização primária é feita em Português, deve-se reconhecer que o desenvolvimento linguístico-cognitivo desses indivíduos ocorre num ambiente de competição linguístico-cultural que propicia as transferências e infelicidades discursivas. Este quadro determina que a performance dos escreventes que participaram na nossa pesquisa seja influenciada por este contexto sociolinguístico e cultural que coloca a língua portuguesa como a dominante e as restantes línguas de raíz bantu, se encontrem subalternizadas. A sociedade moçambicana é um complexo multilingue e multicultural, por isso, qualquer estudo que vise compreender e avaliar a maneira como as pessoas escrevem e falam não pode deixar de se sustentar em abordagens interlinguísticas e interculturais, apoiadas em metodologias contrastivas (cf. LOPES et al., 2016, p. 16-19), as quais endereçam melhor as ocorrências que provocam transferências linguístico-discursivo, culturais e idiomáticas (cf. LOPES, 2004, p. 168).

Para analisarmos a performance do falante/escrevente de Português língua segunda (L2) em termos de grau de fluência e proficiência, pesquisámos o modo como os sujeitos processam o discurso escrito e elicitámos as tendências de processamento linguístico e retórico-discursivo que emergem dos trechos seleccionados.

1 Este artigo foi elaborado com base na tese de doutoramento apresentada na Universidade Eduardo Mondlane, em agosto de 2017, intitulada "Uma abordagem interlinguística e intercultural à linguagem idiomática no discurso escrito em Português redigido por alunos universitários moçambicanos", sob supervisão do Professor catedrático Armando Jorge Lopes. 
Linha D'Água (Online), São Paulo, v. 31, n. 1, p. 145-170, jan.-abril 2018

Neste contexto, elegemos a análise de traços idiomáticos e formulaicos numa situação de comunicação escrita em que predomina o género textual opinativo e o tipo argumentativo, destacando as relevantes formações ${ }^{2}$. Esta noção criada por Lopes (cf. LOPES, 2016b; LOPES et al., 2016, p. 2) no contexto da escola anglosaxónica da análise do discurso deriva da abordagem ao texto e ao discurso iniciada por Widdowson $(1978$, p. 3) que se destacou pelo estabelecimento da dicotomia "language usage"/"language use", das considerações de Malcom Coulthard (2000) sobre a distinção entre texto e discurso e caracterização do discurso como inserido e emanando de práticas sociais. Formação é uma noção eminentemente macrolinguística e, por ser discursiva, está intimamente ligada à abordagem idiomática. Ela ajuda a dar conta das unidades idiomáticas e formulaicas, e permite acomodar os conceitos de formação idiomática e outras sequências formulaicas ou não, incluindo idiomatismos que os escreventes utilizam na comunicação. A noção de idiomaticidade diz respeito a uma sequência de palavras semântica e, muitas vezes, sintacticamente restrita que funciona como uma simples unidade. Do ponto de vista semântico, o significado das palavras individuais não se associa para formar o significado da sequência como um todo e, em termos sintácticos, não admite a variabilidade que assumiriam em outros contextos. Tais sequências são apelidadas de pré-fabricadas e, de acordo com Erman e Warren (2000, p. 31), consistem na "combinação de pelo menos duas palavras que são privilegiadas pelos falantes nativos, em termos de preferência, relativamente a uma outra combinação alternativa que poderia ser equivalente se não existisse uma convencionalização"3

Sobre a convencionalização, Wulff (2008, p. 2) considera que este conceito diz respeito a uma combinação específica de palavras que formam um sintagma,

\footnotetext{
2 Lopes (2016b, p. 24) criou o "termo formulação para referir uma realização discursiva como, por exemplo, um idiomatismo ou qualquer outra categoria idiomática. Seria mais ou menos semelhante a dizer 'estrutura', só que este é um termo do campo microlinguístico". Este conceito evoluirá para formação (ou expressão) em Lopes et al. (2016, p. 2) para se referir "a uma realização discursiva (macrolinguística) como, por exemplo, um idiomatismo ou qualquer outra categoria idiomática. Seria mais ou menos semelhante a dizer 'estrutura', só que este é um termo da microlinguística (quadro da fonologia-à-semântica)".

3 "A pre-fab is a combination of at least two words favored by native speakers in preference to an alternative combination which could have been equivalent had there been no conventionalization" (ERMAN e WARREN, 2000, p. 31).
} 
Linha D'Água (Online), São Paulo, v. 31, n. 1, p. 145-170, jan.-abril 2018

independentemente das formas ou variantes específicas que as palavras constitutivas possam assumir individualmente, essa combinação tem de ser frequente ${ }^{4}$. Estudiosos que se debruçam sobre a formulaicidade concordam que, do ponto de vista cognitivo, os falantes competentes processam a língua, preferencialmente, de modo holístico e só recorrem ao modo analítico quando necessário. Esta posição corrobora a definição de Wray (2002, p. 9), segundo a qual sequência formulaica é "uma sequência, contínua ou descontínua que é ou parece pré-fabricada, isto é, armazenada e recuperada da memória como um todo no momento em que é usada, e não gerada pela gramática da língua"5. [trad. JL, original em Inglês]. Por idiomaticidade, Pawley e Syder (1983, p. 191) assumem

capacidade de o falante nativo exprimir significados de forma rotineira, através de uma expressão que não é apenas gramatical, mas também corresponde à performance do falante nativo. $\mathrm{O}$ que parece problemático nisto, é como é que o falante nativo selecciona uma frase que é natural e idiomática de entre um leque de paráfrases gramaticalmente correctas, e muitas das quais não correspondem a realizações nativas. [trad. JL, original em Inglês] ${ }^{6}$.

Das definições acima, pode-se extrapolar que a idiomaticidade e a formulaicidade se situam mais ao nível do uso do que da gramática e que o processamento mental ou cognitivo, o conhecimento gramatical e de uso são críticos na interacção linguística. Assim se compreende a associação entre formulaicidade e idiomaticidade ao conceito de fluência, entendida como a habilidade de usar a língua com facilidade, correcção e adequação, mais centrada nas funções da linguagem; e com

4 "By conventionalization, I mean that the specific combination of words constituting the phrase, regardless of the specific variant forms the individually component words take on, has to be sufficiently frequent" (WULFF, 2008, p. 2) (Destaques do autor).

5 "A sequence, continuous or discontinuous of words or other meaning elements, which is, or appears to be prefabricated: that is, stored and retrieved whole from memory at the time of use, rather than being subject to generation by the language grammar" (WRAY, 2002, p. 9).

6 "The ability of the native speaker to routinely convey his meaning by an expression that is not only grammatical, but also native like; what is puzzling about this is how he selects a sentence that is natural and idiomatic from among the range of grammatically correct paraphrases, many of which are non-native like or highly marked usages" (PAWLEY e SYDER, 1983, p. 191). 
Linha D'Água (Online), São Paulo, v. 31, n. 1, p. 145-170, jan.-abril 2018

o conceito de proficiência, entendido como a manifestação de um tipo geral de competência no uso da língua para um determinado propósito.

Conforme Halliday (1985, p.xiv), a gramática funcional providencia os instrumentos de explanação das possibilidades de escolha ou preferência por certas construções em determinados contextos e situações de comunicação. Enquanto a gramática formal se ocupa, sobretudo, do significado das formas das palavras, a gramática funcional procura a explicação de como tais significados são expressos, tratando as formas linguísticas e outras como um meio para se alcançar um fim, e não um fim em si mesmo.

Justifica-se, portanto, que a presente investigação tenha privilegiado abordagens discursivas, sobretudo nas suas dimensões funcionais e cognitivas, uma vez que as sequências em estudo não podem ser descartadas das suas funções pragmáticas e discursivas no contexto mais amplo em que são usadas. Na vertente cognitiva, para chegarmos à elicitação e sistematização das regularidades sobre a natureza, conhecimento e uso das unidades e dos mecanismos formais, através dos quais as pessoas adquirem, armazenam e recuperam sequências idiomáticas e formulaicas, baseámo-nos nos dados produzidos pelos Sujeitos da pesquisa. Conforme estabelecidas por Lopes (2016) na introdução à obra de Lopes et al. (2016, p. 7-17), as categorias de análise da idiomaticidade e formulaicidade, permitem equacionar o sucesso da comunicação com o grau de conhecimento partilhado do código linguístico, das convenções retórico-discursivas e de dimensões não-linguísticas da experiência, incluindo a sua visão do mundo (schemata/estruturas cognitivas) (cf. LOPES, 2013c; LANGA, 2010, p. 8-10; WIDDOWSON (1983b, p. 36-37). Neste contexto, o pesquisador pode avaliar a capacidade macrolinguística dos escreventes e até que ponto dominam as regras de uso formal ("language usage") e as regras de uso funcional ("language use").

\section{Quadro teórico-metodológico}

Idiomaticidade e formulaicidade são traços presentes no processamento do discurso para efeitos de produção e de compreensão da língua por falantes nativos (cf. LOPES, 2004, p. 81; MEDGYES, 1994, p. 9-11; 16; LOPES, 1982, p. vii;), 
Linha D'Água (Online), São Paulo, v. 31, n. 1, p. 145-170, jan.-abril 2018

quase-nativos (cf. MEDGYES ibid., p. 14-17; LOPES et al. (2016, p. 16) ou nãonativos e, para a sua abordagem, requerem perspectivas macrolinguísticas e funcionais. Macrolinguística é um termo usado na linguística para designar uma abordagem ampla do tópico da investigação linguística, buscando as unidades da sua organização, para além da mera frase e tem por finalidade atingir uma compreensão científica sobre como as pessoas comunicam (JAMES, 1980, p. 100-103), tendo em conta que o conhecimento da língua é condição necessária, mas não suficiente no processo de comunicação. Nesse sentido, a macrolinguística integra uma área que se preocupa pela competência comunicativa, portanto, pelo discurso enquanto produto, do que pela competência linguística, ou seja, pelo discurso como processo. A outra, tenta descrever os eventos linguísticos no seio dos conjuntos extra-sociais, privilegiando considerações de carácter pragmático. Entendidos desta maneira, os estudos macrolinguísticos integram uma orientação de análise do discurso como processo (cf. LOPES, 2004, p. 209), por oposição à consideração do texto como produto. A abordagem interlingue e intercultural facilita a análise das condições de felicidade, das infelicidades discursivas e idiomáticas, assim como os diferentes tipos de schemata que marcam especificidades no uso da língua portuguesa por escreventes de L2 será apoiada por uma combinação de modelos de base cognitiva.

O modelo de Wood (2010) que descreve os processos psicolinguísticos envolvidos no desenvolvimento da fluência numa L2; o modelo de processamento dual de Sinclair (1991), segundo o qual no processamento do significado, tanto para efeitos de produção, como de compreensão estão disponíveis dois princípios por ele designados de princípio de escolba aberta ("open choice principle”) e o princípio idiomático; o modelo do léxico-heteromórfico distribuído de Wray (2002), na versão de Lewis (2009), que relaciona o processamento linguístico e o neurolinguístico com a especialização e localização das categorias e subcategorias de léxico e as funções a que correspondem na comunicação em cada um dos dois hemisférios cerebrais; a teoria da predição de Tadros (1985) dando conta de que a estruturação do texto escrito opera ao nível da cognição e mobiliza o conhecimento proposicional, referencial e pragmático para o processamento do discurso pelos participantes na interacção comunicativa. O modelo de análise de Lopes [(2015a); (2016b)] e Lopes et al., (2016) referente a formações idiomáticas e formulaicas que estabelece 
Linha D'Água (Online), São Paulo, v. 31, n. 1, p. 145-170, jan.-abril 2018

categorias e subcategorias orientadas para três vectores, nomeadamente a idiomaticidade; a co-ocorrência; e a formulaicidade.

\section{Análise dos dados}

Os trechos que analisamos foram extraídos de composições escritas por alunos do curso de Licenciatura em Ensino de Português da UEM, das quais se pretendia elicitar a habilidade linguística e discursiva na produção de um texto argumentativo. $\mathrm{Na}$ análise buscámos traços idiomáticos e formulaicos que contribuem para a fluência e para a expressão de schemata.

\subsection{Texto A - Título: Médicos tradicionais viraram negociantes em Moçambique}

Através do título, o escrevente inicia a interacção com os interlocutores, antecipando a perspectiva pela qual tenciona desenvolver o conteúdo. À partida, reconhece a legitimidade, a dignidade, o valor social e cultural desta área e dos seus profissionais. Mas ao revelar que viraram negociantes, por antecipação, o leitor fica preparado para um debate crítico do comportamento de certos médicos tradicionais no mercado. $\mathrm{O}$ mundo cósmico do escrevente revela-se, de imediato, nos dois primeiros segmentos da unidade textual, abaixo, e vai-se completando à medida que ataca os médicos mercantilistas e defende os outros que são sérios na sua actividade. $\mathrm{O}$ escrevente partilha a sua visão do mundo com o leitor, partindo da tese de que:

(1) A medicina tradicional é uma forma de tratamento de certas doenças em que são usados medicamentos produzidos tradicionalmente. Em Moçambique esta medicina é legal e os seus praticantes são chamados médicos tradicionais. Nos últimos dias tem-se verificado muitas publicidades destes serviços nos diversos meios de comunicação e até colados nas paredes. Na verdade, nem são todos os serviços que eles prestam com eficiência, o que mais querem é ganhar dinheiro. 
Linha D'Água (Online), São Paulo, v. 31, n. 1, p. 145-170, jan.-abril 2018

Neste trecho, apesar de o escrevente utilizar os recursos coesivos adequadamente, do ponto de vista linguístico e discursivo (ver os itens sublinhados), no conjunto, o seu enunciado confunde o leitor porque não são visíveis as ligações entre as várias proposições. Estão ausentes as formas linguísticas e retóricas de expressão de relações lógicas ou de hierarquização das proposições, isto é, os marcadores discursivos de técnicas retóricas, assim como as sequências sintagmáticas se afastam das formas habituais ou convencionais aceites na língua. Quando isto se verifica, o texto perde idiomaticidade, o que em termos mais simples significa perder naturalidade.

A primeira ideia, coincidente com o primeiro período, pretende ser uma definição, mas esta falha por ser, de certo modo falsa, em termos de valor de verdade e, por consequência, não tem valor fora do mundo textual, pois não é verdade que a medicina tradicional seja uma forma de tratamento. Esta definição peca por ser circular, ao definir medicina tradicional pelos termos do próprio conceito: o leitor não obteve informação nova, nem partilhou, nem negociou informação ou conhecimento (WIDDOWSON, 1983b).

No segundo segmento, o leitor depara-se com informação que parece ter sido encaixada, mas a função discursiva e informativa desse encaixe não é clara. Esperar-se-ia que aspectos da legalização ou aceitação pública desta medicina viessem a ser tratados no texto. Apesar da correcção sintáctica, neste segmento parece haver descontinuidade discursiva e não há qualquer tipo de relação com os dois segmentos anteriores que, aparentemente, reflectem um discurso com maior coesão textual e coerência funcional e com maior força preditiva entre si.

Ao ler o início da penúltima unidade discursiva, o leitor espera que o escrevente verse sobre algo relacionado com a publicidade dos serviços dos médicos tradicionais. A predição será efectivamente realizada com o fecho da tese, onde ou quando o escrevente coloca o seu ponto com a respectiva orientação e a perspectiva que vai tomar na problematização da questão:

(2) Na verdade, nem são todos os serviços que eles prestam com eficiência, o que mais querem é ganhar dinheiro. 
Linha D'Água (Online), São Paulo, v. 31, n. 1, p. 145-170, jan.-abril 2018

De uma maneira geral, o autor do trecho (1) mostra conhecer as regras formais da língua, relacionadas com correcção (accuracy), mas na sua performance demonstra não ter conseguido usar o seu conhecimento (competência) de modo apropriado, com facilidade, naturalidade e com sentido de auto-confiança, para que o seu discurso seja considerado fluente [(cf. LEWIS, 2009, p. 11 e LOPES et al., 2016, p. 14-16)]. Igualmente, notamos que embora se tenha proposto a organizar as suas ideias para um discurso argumentativo, não conseguiu mobilizar (ou não possui ainda o domínio de uso) as unidades formulaicas que geralmente sustentam a fluência e a proficiência, ligando e cimentando as formações discursivas. Por isso, não estão presentes conectores lógicos, nem mecanismos ou estratégias linguístico-discursivas que facilitem a hierarquização dos enunciados, visando tornar o discurso do ponto de vista pragmático adequado e consentâneo com as condições de felicidade. O princípio de que "falar uma língua é realizar actos de fala referenciais e predicativos de acordo com certas regras de uso da língua” (cf. SEARLE, 1999, p. 68; AUSTIN, 1962, p. 1-4; LEECH, 1983, p. 9, 176) ajuda a avaliar a competência do escrevente.

A ausência de idiomaticidade e de formulaicidade na produção de falantes de L2 ou LE pode dever-se à qualidade da exposição à língua e ao estilo de aprendizagem. Podendo não ser totalmente o caso do trecho (1), julgamos que a extrapolação é relevante para reafirmarmos a falta naturalidade quando um falante/escrevente se exprime através da concatenação de enunciados, como se estivesse a usar uma linguagem do tipo "baby talk". Relativamente à capacidade de processamento cognitivo na produção escrita, poderíamos dizer que, provavelmente, o escrevente ainda não consolidou as habilidades de conversão do conhecimento declarativo em conhecimento procedural (WOOD, 2010, p. 2-6) de modo a realizar actos de fala felizes.

Seguindo Sinclair (1991, p. 110) e confrontando com Wray (2002, p. 9), constatamos que há sinais de que o princípio idiomático não é predominante, se tivermos em conta o início hesitante dos dois primeiros períodos, revelando um estilo de processamento mais analítico. Nos dois últimos, o escrevente mostra maior segurança, o discurso parece fluir melhor e começa a transparecer um modo de processamento mais holístico.

A ocorrência da formação muitas publicidades, porque em português publicidade não é quantificável, parece violar a forma convencionalizada ou maneira 
Linha D'Água (Online), São Paulo, v. 31 , n. 1, p. 145-170, jan.-abril 2018

habitual de dizer, retirando a naturalidade esperada pelo leitor e falante nativo ou proficiente da língua portuguesa. Mas, dado que houve muitas ocorrências desta forma em outras composições, é provável que ela esteja a se cristalizar. Esta e outras formações podem ser abordadas conforme Lopes (2016, p. 14) sugere, assumindo "a linguagem formulaica ou linguagem pré-fabricada (WRAY, 2002) como um tipo de sobregeneralização, isto é, um processo em que o falante utiliza uma formulação discursiva muito para além do seu uso aceitável”. Formações que se distanciam do significado e uso das sequências de palavras que as sustentam podem ser analisadas numa perspectiva pragmática, uma vez que na comunicação a preocupação não é para com o significado da formação em si, "mas para com o significado que o produtor confere a uma expressão, quando a usa" (WIDDOWSON, 1983b, p. 37). A formação nem são, pode merecer dois tipos de tratamento: a abordagem microlinguística da gramática formal que não admite a ocorrência de nem fora da locução descontínua nem... nem; ou considerar este uso como aceitável na linha dos princípios pragmáticos e formulaicos, fazendo desta forma sinónima e equivalente de não, uma vez que ambas são portadoras da mesma força ilocutória no contexto. $\mathrm{Na}$ segunda unidade discursiva, o escrevente elabora o desenvolvimento da sua tese consistente com a situação ou problema que expôs inicialmente, e deixa transparecer os seus schemata culturais. Os argumentos que tece são no sentido de convencer o leitor de que existem curandeiros interessados somente no dinheiro, e não em curar doenças, o que, para ele, não é comum na medicina tradicional.

A opinião que prevalece da discussão-explicação é a de que os médicos tradicionais sérios não publicitam os seus serviços e não evocam actos impossíveis e que a maioria dos que fazem publicidade dos seus serviços visam apenas o lucro e não tratar os doentes. Do ponto de vista cognitivo, ao introduzir o seu discurso e o tema (trecho 1), o escrevente propõe-se a realizar uma intenção comunicativa, através de uma sequência de formações, cumprindo funções retóricas de construção de uma tese ou colocação de uma situação-problema. Contudo, entre essas formações, não há nenhuma relação retórica. De facto, não é evidente a operação de técnicas retóricas para exprimir eventuais relações de ordem temporal ou espacial, de causalidade e resultados, entre outras. $\mathrm{O}$ escrevente serve-se de rotinas 
Linha D'Água (Online), São Paulo, v. 31, n. 1, p. 145-170, jan.-abril 2018

conversacionais que nos alertam para os actos de fala que se seguirão. No caso vertente, essa introdução é sinalizada pela formação:

(3) Para melhor entendermos esta realidade basta analisarmos alguns dos seguintes aspectos das suas publicidades.

O que escreve, em seguida, parece não estar em linha de coesão discursiva com o anunciado em (3) através das rotinas conversacionais sublinhadas. $\mathrm{O}$ discurso prossegue desligado, principalmente, porque a expectativa do leitor de ir ao encontro de uma enumeração e/ou da análise dos referidos ...seguintes aspectos das suas publicidades ou de uma explicação foi gorada. Em vez disso, o escrevente recorreu a uma função retórica para comparar, por via do contraste, o conteúdo informativo da mensagem publicitária com a condição real da vida dos médicos tradicionais. No trecho (4) nota-se que as formações perdem sentido porque a incoesão discursiva, principalmente com origem na selecção lexical, dá lugar a transferências linguísticas, discursivas e culturais, como se pode ver no trecho a seguir:

(4) Os médicos tradicionais colocam nas suas publicidades que curam HIV/ SIDA; mas nunca ninguém apareceu publicamente a confirmar a sua cura. É possível encontrarmos na publicidade de um médico tradicional uma informação que diga que ele é capaz de fazer alguém enriquecer, enquanto ele próprio é pobre. Face a estas situações, a Associação dos Médicos Tradicionais de Moçambique, apelou ao povo moçambicano sobre a existência em Moçambique de médicos interessados no dinheiro e não em curar doenças.

As evidências que reafirmam a tese do escrevente, em termos de formulação e de conteúdo ocorrem, conforme se espera, na conclusão e no fecho do texto (vide excertos mais abaixo). $\mathrm{O}$ não-recurso à publicidade e à não-cobrança prévia ao sucesso confirmado dos tratamentos justificam e provam a existência de um sector de médicos tradicionais sérios, que não visam o lucro. 
Linha D'Água (Online), São Paulo, v. 31, n. 1, p. 145-170, jan.-abril 2018

(5) Admite-se, entretanto, a existência de outros que são sérios na sua actividade, cobram as suas taxas depois dos efeitos positivos do tratamento. Estes geralmente não fazem publicidades evocando actos impossíveis.

(6) Para terminar, é importante dizer que a maior parte dos médicos tradicionais que fazem publicidades e colam nas paredes e muros, evocando a cura de doenças até hoje incuráveis tem finalidades lucrativas e não de ajudar aos seus crentes.

O escrevente anuncia a função retórica de fecho do discurso, fazendo operar padrões de ordem temporal como para terminar e até hoje que, ao mesmo tempo, são fórmulas de expressão de rotinas estilísticas que localizam o leitor no tempo do discurso e dos eventos. Juntamente com a rotina conversacional é importante dizer que, estas fórmulas constituem-se em muletas retóricas, preparam o leitor para o fim do texto e reafirmam a tese. Os aspectos que denunciam a visão do mundo do escrevente são notáveis pela forma como ele, espontaneamente, exprime o seu pensamento através de estruturas que linguística, lógica e semanticamente se afastam das habitualmente produzidas e aceites por falantes nativos ou quase-nativos:

(7) Os médicos tradicionais colocam nas suas publicidades que curam HIV/ SIDA; mas nunca ninguém apareceu publicamente a confirmar a sua cura.

(8) É possível encontrarmos na publicidade de um médico tradicional uma informação que diga que ele é capaz de fazer alguém enriquecer, enquanto ele próprio é pobre.

Do ponto de vista cognitivo, a organização do conteúdo dos dois excertos acima revela que o escrevente conhece o tópico e o contexto, e que ele elabora o seu discurso colocando-se como advogado da "verdadeira" medicina tradicional. Os detalhes destacados testemunham que o escrevente detém o conhecimento do padrão de vida e algumas questões éticas que vinculam os médicos tradicionais a certas maneiras de estar nas comunidades e de relacionamento com os respectivos 
Linha D'Água (Online), São Paulo, v. 31 , n. 1, p. 145-170, jan.-abril 2018

clientes. Na língua e cultura portuguesa e na(s) língua(s) e cultura(s) bantu a formação ele é capaz de fazer alguém enriquecer, enquanto ele próprio é pobre são processados e interiorizados de maneira completamente diferente. Na cultura ocidental, esta formação é processada literalmente e, provavelmente, não penetra no mundo ali representado. Por isso, nesta perspectiva, o questionamento faz sentido. Uma interpretação feita por membros de culturas bantu consideraria esta formação uma heresia, porque estaria a pôr em causa todo um sistema de crenças.

\subsection{Texto B}

Da temática dada, o escrevente elegeu os conflitos familiares, como a perspectiva pela qual iria explorar o tema e dele destacamos os schemata culturais e de conteúdo que emergem. Notámos que a palavra serviços é diferente de como a aplicamos no enunciado das composições (... serviços prestados pelos médicos tradicionais). Começamos a perceber que, por serviços, o escrevente entende: os remédios, as magias, as rezas e rituais assumidos semanticamente como coisas (que se usam, que se aplicam, etc.). Por exemplo, a agulha tratada para ser espetada no bolso do marido. Veja-se o contexto linguístico e situacional no extracto que se segue:

(9) ... as mulheres aderem aos serviços dos médicos tradicionais para domar até mesmo matar os seus maridos a fim de herdar os bens materiais que estes possue [possuem] ...uma mulher está em contenda com a família do marido, por ter espetado no bolso deste uma agulha tratada pelos serviços destes médicos para matar o esposo.

Neste e no trecho seguinte, encontramos usos linguísticos que só fazem sentido numa análise que privilegie aspectos extralinguísticos. Estas realidades existem em culturas particulares não representadas na língua portuguesa, em que não são concebíveis certos actos mágico-religiosos realizados pelos curandeiros, como tratar-se e mandar/fazer enlouquecer alguém e, por isso, não verbalizáveis desta maneira. 
Linha D'Água (Online), São Paulo, v. 31, n. 1, p. 145-170, jan.-abril 2018

(10) ... muitos homens ao verem que as suas vidas materialmente não correm bem, dirigem-se aos serviços de crenças para se tratar e mandar enlouquecer um dos membros da linhagem (neto, filho, sobrinho) para que espiritualmente este seja o garante da entrada de moeda (capital) e sucesso no negócio.

Nos dois trechos acima somos colocados perante uma visão estereotipada sobre os interesses típicos de mulheres e homens, interesses esses que os levam a recorrer aos serviços da medicina tradicional. Talvez pela natureza do tópico, os trechos (9) e (10) apresentam uma densidade grande de linguagem culturalmente marcada que pode ser considerada idiomática na língua e/ou cultura fontes. Tiramos esta conclusão porque a organização das formações idiomáticas e quase-idiomáticas e o conteúdo que encapsulam não encontram correspondência em categorias similares da língua e cultura portuguesa.

\subsection{Texto C}

Neste texto, o escrevente refere-se à publicidade dos médicos tradicionais e não à publicidade dos serviços dos médicos tradicionais. As técnicas retóricas são orientadas para contextualizar o leitor, através do uso de padrões temporais e espaciais, no tema geral do discurso. Para isso, começa com uma localização temporal genérica nos dias de hoje e depois associa esta a localizações de ordem espacial genérica e específica: ao longo das vias de acesso da cidade de Maputo; nas chapas, bem como nos painéis; nesse ponto do país. Para se referir à publicidade o escrevente usou a estratégia da descrição escritas nas chapas e painéis, uma formação baseada na repetição, dado que chapas [publicitárias] e painéis [de publicidade, ("outdoor")] no contexto publicitário são sinónimos. Ocorre-nos, no entanto, que, embora tenham a função comum de exibir informação, as duas palavras foram tratadas de forma distinta pelo escrevente, com base no seu conhecimento extralinguístico. $\mathrm{Na}$ comunidade chapas têm geralmente um formato quadrado ou rectangular, feitas de pedaços de zinco ou qualquer outro material metálico, plástico; de madeira ou papel-cartão onde se inscrevem informações publicitando, entre outros, os serviços dos médicos tradicionais. Enquanto por painel, se designa o painel publicitário convencional 
Linha D'Água (Online), São Paulo, v. 31, n. 1, p. 145-170, jan.-abril 2018

feito de materiais diversificados. Pode ser luminoso ou não, electrónico, etc. e é edificado nas praças, passeios e esquinas das cidades e vilas, nos terraços dos prédios, anexado a postes de iluminação para divulgar produtos e serviços de vários.

As designações chapas e painéis, conforme ocorrem neste discurso escrito, podem ser reveladoras de schemata por parte do escrevente que faz questão de sublinhar dois mundos da publicidade: um formal e convencional, feito de matérias de suporte de um certo nível de sofisticação; e outro informal, natural com o uso de suportes toscos. Enquanto no excerto (11) encontramos uma formação idiomática bem usada de acordo com as regras e rincípios de uso da língua- alvo:

(11) ... essa estratégia de difundir as informações nos espaços públicos ... é uma janela de oportunidade para o aparecimento de falsos médicos tradicionais.

Nos exemplos a seguir:

(12) ...é um fenómeno bastante triste o que temos visto nas ruas e espaços públicos

(13) ...entram em contradição com a ciência porque as doenças cientificamente comprovadas as mensagens alegam que curam as doenças.

encontramos formas de expressão peculiares de línguas de raíz e cultura bantu que merecem destaque pela forma particular de organização dos significados que veicula. Elas não reflectem exactamente infelicidades, mas sim a ocorrência de transferências intradiscursivas na L2 (isto é, transferências internas ao nível da própria língua-alvo, e não de uma língua interferindo noutra).

\subsection{Texto D}

O texto $\mathrm{D}$ intitulado Os médicos tradicionais curam doenças crónicas exibe uma transferência linguístico-cultural, resultante da tradução (?) directa de um item lexical.

(14) Trabalham com raízes medicinais para o curativo de algumas doenças. 
Linha D'Água (Online), São Paulo, v. 31 , n. 1, p. 145-170, jan.-abril 2018

A raíz não é a única parte das plantas que se usa na medicina tradicional, mas em línguas como o Xirhonga e o Xichangana, por exemplo, em vez de remédios, diz-se o Sr. João usa 'raizes' [lit.] para curar os seus doentes ou o Sr. João usa 'arvores' [lit.] para curar os seu spacientes, em oposição a outras correntes de médicos tradicionais que usam animais [lit.] (extractos ou partes de) ou pessoas. Também se pode fazer um elogio a alguém por conhecer raízes ou árvores, em vez da forma corrente portuguesa 'plantas/ervas', para se referir a plantas utilizadas pelos médicos tradicionais. O termo curativo foi mal selecionado, portanto não só é incorrecto como é inapropriado no cotexto, assim como no contexto situacional. Com esta forma confunde-se a cura, como resultado de vários passos do processo médico, com a acção específica de tratar uma ferida/ferimento. Outras ocorrências de curativo para significar cura ou tratamento revelam que o escrevente atribui múltiplos significados, como uma criança em fase de formulação de hipóteses sobre o(s) significado(s) e uso(s) de uma palavra nova. Vejamos as diferentes ocorrências:

(15) O curativo desta medicina, está aberto para todos doentes

(16) Os médicos tradicionais... preparam os curativos tendo em conta que a doença foi desistida pelos médicos hospitalares

(17) ... as raízes ...para os curativos das doenças são muito flexíveis

(18) ... ajudam e facilitam aos médicos hospitalares nos curativos das doenças

(19) ... ajuda os curativos de doenças obtidas por feitiço

(20) ... dão os primeiros socorros

(21) ... dão o diagnóstico.

A formulação a doença foi desistida pelos médicos é anómala em Português. Entretanto, no conjunto, o enunciado revela transferência discursiva de schemata culturais, reflectidas na forma linguística desta formulação. Este contexto de uso denuncia 
Linha D'Água (Online), São Paulo, v. 31, n. 1, p. 145-170, jan.-abril 2018

a presença de uma transferência negativa, que pode ser resultado de uma transposição literal das línguas bantu, como do Xichangana ou do Xirhonga para o Português de... a doença foi desistida pelos médicos de mavabgui ma lhuli vadokodela [lit.: A doença venceu os doutores] = Vadokodela va tsandzekiwile hi mavagui [lit.: 'Os doutores não conseguiram com a doença']. Ao redigir o texto, o escrevente não teve em conta particularidades de certas componentes de sentido que se situam fora da estrutura linguística. Esse tipo de componentes é responsável pela maioria dos problemas de equivalência ${ }^{7}$ entre a língua portuguesa e as línguas de raíz bantu.

No exemplo doenças obtidas por feitiço detectámos a presença de schemata culturais, o que revela a visão do mundo do escrevente sobre a origem e a causa das doenças. Neste caso, observamos também que a formação deveria reflectir os factos como acontecem no mundo real, ou seja, o facto de que as doenças não se obtêm, mas sim, contraem-se; e que as doenças não são obtidas, mas causadas. As relações lógicas de causa e efeito foram mal expressas e deram lugar a uma formação infeliz, em circunstâncias tais que, mesmo havendo equivalência dos traços de sentido, o produtor não conseguiu estabelecer uma equivalência idiomática entre as formas do discurso da sua língua materna para o português e seleccionar as palavras mais adequadas do Xichangana para o Português:

(22) Mavagui ya ku vanguiwa hi uloy [lit.: doenças causadas por feitiço].

Nos dois últimos exemplos, o verbo dar está sendo usado em lugares onde o mais apropriado seria fazer, pois, diagnósticos fazem-se ou são feitos, e primeiros socorros prestam-se. Estes fenómenos podem ser explicados sob o conceito de colocação (collocation) e da teoria de marcação lexical ("lexical priming") de Hoey (2005), para quem colocação “é um agrupamento familiar de palavras, especialmente palavras que ocorrem juntas, transmitindo um significado por associação e funcionando a um nível lexical de análise”. O que nos faz rejeitar doenças obtidas por feitiço e dão diagnósticos e logo substituir essas ocorrências por contraídas/causadas e prestar é que:

7 Veja-se o estudo de Julieta Langa publicado na Folha de Linguística e Literatura 10, p. 1417.

LANGA, J. M. A idiomaticidade e a formulaicidade no discurso escrito em português produzido por 
Linha D'Água (Online), São Paulo, v. 31 , n. 1, p. 145-170, jan.-abril 2018

\begin{abstract}
Essas palavras devem estar, à partida, e em considerável medida, marcadas lexicalmente [lexically primed] para participarem em cadeias de coesão (colocação textual) e eu acrescentaria, participando igualmente em cadeias de coerência (em que teríamos a colocação discursiva). Segundo Hoey (op. cit.), uma palavra marcada psicologicamente provoca, em geral, uma determinada palavra-alvo (destaques do autor) (LOPES et al., 2016, p. 13).
\end{abstract}

Neste sentido, ao dizer-se doenças, vem mais rapidamente à mente o verbo causar ou contrair do que obter.

\title{
Conclusão
}

Analisámos as formações extraídas de quatro textos com o objectivo e identificar formações idiomáticas e formulaicas e outros elementos linguísticos e retórico-discursivos reveladores de como os escreventes expressam a sua visão do mundo quando escrevem em Português. Verificamos que o conhecimento e uso inadequados de marcadores discursivos é uma das causas da falta de naturalidade que leva à perda de idiomaticidade, contribuindo para a redução da fluência e proficiência na língua-alvo e responsável pelas anomalias retórico-discursivas na escrita em Português L2.

A expressão de schemata culturais é prejudicada pelo domínio desequilibrado de traços de idiomaticidade entre a língua portuguesa e da sua língua materna. Os schemata estão vinculados ao mundo real e, quando os escreventes têm de se expressar acerca de realidades culturais específicas da sua cultura, parecem fazê-lo com certa espontaneidade, porque têm bom conhecimento do assunto, enquanto membros de uma certa comunidade cultural. Mas, paradoxalmente, falham na comunicação porque não conseguem usar os recursos do Português de forma idiomática. Enfrentando, consciente ou inconscientemente, dificuldades de acesso a traços de equivalência linguística, discursiva e idiomática, os escreventes procedem à transposição literal para o Português, resultando em transferências discursivas negativas de schemata culturais.

Em muitos dos trechos que tratamos é sensível a distância linguístico-cultural manifesta pela presença de formações culturalmente marcadas com forte robustez idiomática quando analisadas na perspectiva discursiva da língua e cultura (fontes) 
Linha D'Água (Online), São Paulo, v. 31, n. 1, p. 145-170, jan.-abril 2018

de raíz bantu. Quando os escreventes procuram expressar relações lógicas de causa e efeito dão lugar a formações infelizes. Apesar de, por vezes, haver equivalência dos traços de sentido, eles não conseguiram alcançar a equivalência idiomática entre o discurso da sua língua materna e a do Português. Nessas circunstâncias, o produto discursivo é afectado pela falta de naturalidade e afasta-se das formas habituais ou convencionais aceites na língua-alvo.

\section{Referências}

AUSTIN, J.L. How to Do Things with Words. Oxford: Oxford University Press, 1962.

ERMAN, B. e WARREN, B. The idiom principle and the open choice principle. Text 20:1, p. 29-62, 2000.

HALLIDAY, M.A.K. An introduction to functional grammar. Londres: Edward Arnold, 1985.

HOEY, M. Lexical priming: a new theory of words and language. Londres: Routledge, 2005.

JAMES, C. Contrastive analysis. Londres: Longman, 1980.

LANGA, J.M Uma abordagem interlinguística e intercultural à linguagem idiomática no discurso escrito em Português redigido por alunos universitários moçambicanos. Tese de Doutoramento (não-publicada). Maputo: UEM, 2017.

LANGA, J.M. Para uma abordagem das estruturas cognitivas: cenários interpretativos do texto “A morte de um homem organizado". Folba de Linguística e Literatura 13, p. 8-13, 2009.

. Esboço para uma análise da equivalência no léxico de usos. Folha de Linguística e Literatura 10, p. 14-17, 2007.

LEECH, G. Principles of pragmatics. Londres: Longman, 1983.

LEWIS, M. The idiom principle in L2 English: assessing elusive formulaic sequences as indicators of idiomaticity, fluency, and proficiency. Estocolmo: VDM Verlag Dr. Müller Aktiengesellschaft \& Co, 2009.

LANGA, J. M. A idiomaticidade e a formulaicidade no discurso escrito em português produzido por 
Linha D'Água (Online), São Paulo, v. 31, n. 1, p. 145-170, jan.-abril 2018

LOPES, A.J. A batalha das línguas nos PALOPs e a tradução da Bíblia. Comunicação de abertura (keynote address) ao seminário lusófono de capacitação em tradução e consulta da Bíblia, Maputo: Sociedade Bíblica de Moçambique, 2016a.

Comunicação translinguística e transcultural com enfoque na linguagem idiomática: Uma Análise Contrastiva Discursiva entre o Português, Xichangana e Inglês. São Paulo: Todas as Letras [Revista de Língua e Literatura da Universidade Presbiteriana Mackenzie-SP 18/1, p. 22-36, 2016b.

Géneros textuais e tipos textuais. Texto para o curso de doutoramento em ciências da

linguagem aplicadas ao ensino de línguas. Universidade Pedagógica, Maputo, Outubro [mimeo], 2015a.

Some aspects of Portuguese word order and its communicative function. Tese de Mestrado (não publicada). UK: University of York, 1982.

. MABASSO, E., LANGA, P. Com Todos os Efes e Erres: Para um Léxico de Usos Idiomáticos-Português-Inglês-Xichangana /With All The Bells and Whistles: Towards a Lexicon of Idiomatic Usage- Portuguese-English-Shangaan / Kudlaya Nsuna ni Bawa: Ta Kukongoma Marito ya kufambelana ni Kutirhisa Svivulavulelo-Xiputukesi-Xinghiza-xichangani. Maputo, UEM: Livraria Universitária, 2016.

MEDGYES, P. The non-native teacher. Hong Kong: MacMillan Publishers, Lda, 1994.

PAWLEY, A.; SYDER, F. Two puzzles for linguistic theory: Nativelike selection and nativelike fluency.In RICHARDS, C. ; e SCHMIDT, R. W. (eds.) Language and communication, p. 191226. London: Longman, 1983.

SEARLE, J.R. Speech acts: an essay in the philosophy of language. Cambridge: Cambridge University Press, 1999 [1969].

SINCLAIR, J. Corpus, concordance, collocation. Oxford: Oxford University Press, 1991.

TADROS. A. Prediction in text. Birmingham, University of Birmingham, 1985.

WARREN, B. A model of idiomaticity. Nordic Journal of English Studies. 4 (i) p. 35-54, 2005.

LANGA, J. M. A idiomaticidade e a formulaicidade no discurso escrito em português produzido por 
Linha D'Água (Online), São Paulo, v. 31, n. 1, p. 145-170, jan.-abril 2018

WIDDOWSON, H.G. New starts and different kinds of failure. In FREEDMAN, A.; PRINGLE, I.; e YALDEN, J. (eds) Learning to write: first language/second language. Nova Iorque: Longman, 1983.

WIDDOWSON, H.G. Learning purposes and language use. Oxford: Oxford University Press, 1983a.

WOOD, D. Formulaic language and second language speech fluency. Nova Iorque: Continuum International Publishing Group, 2010.

WULFF, S. Rethinking idiomaticity: a usage-based approach. Londres: Continuum International Books, 2008.

Recebido em 07/01/2018.

Aprovado em 03/03/2018. 
Linha D'Água (Online), São Paulo, v. 31, n. 1, p. 145-170, jan.-abril 2018

\section{Anexos}

Texto A: Médicos tradicionais viraram negociantes em Moçambique

A medicina tradicional é uma forma de tratamento de certas doenças em que são usados medicamentos produzidos tradicionalmente. Em Moçambique esta medicina é legal e os seus praticantes são chamados médicos tradicionais. Nos últimos dias tem se verificado muitas publicidades destes serviços nos diversos meios de comunicação e até colados nos muros e paredes. $\mathrm{Na}$ verdade, nem são todos os serviços publicados que eles prestam com eficiência, o que mais querem é ter mais clientes e ganhar dinheiro. Para melhor entendermos esta realidade basta analisarmos alguns dos seguintes aspectos das suas publicidades. Os médicos tradicionais colocam nas suas publicidades que curam HIV/SIDA; mas nunca ninguém apareceu publicamente a confirmar a sua cura. É possível encontrarmos na publicidade de um médico tradicional uma informação que diga que ele é capaz de fazer alguém enriquecer, enquanto ele próprio é pobre. Face a estas situações, a Associação dos Médicos Tradicionais de Moçambique, apelou ao povo moçambicano sobre a existência em Moçambique de médicos interessados no dinheiro e não em curar doenças. Existem praticantes desta medicina que cobram dinheiro, mesmo antes dos resultados do tratamento, o que não é comum na medicina tradicional.

Admite-se, entretanto, a existência de outros que são sérios na sua actividade, cobram as suas taxas depois dos efeitos positivos do tratamento. Estes geralmente não fazem publicidades evocando actos impossíveis.

Para terminar, é importante dizer que a maior parte dos médicos tradicionais que fazem publicidades e colam nas paredes e muros evocando a cura de doenças até hoje incuráveis tem finalidades lucrativas e não de ajudar aos seus crentes.

\section{Texto B}

A medicina tradicional é um conjunto de práticas tradicionais e culturais, baseadas no uso de raízes, folhas e ramos de plantas ou árvores e mais, com a finalidade de curar doenças, repelir certos males espirituais e dar a sorte. 
Linha D'Água (Online), São Paulo, v. 31, n. 1, p. 145-170, jan.-abril 2018

Recentemente com o desenvolvimento e espanção [expansão] de jornais, os médicos tradicionais afixam macivamente [massivamente] muitos panfletos como espécie de publicidade nos espaços públicos das cidades. Efectivamente, a publicidade dos serviços pelos médicos tradicionais nos espaços públicos da cidade de Maputo é o motivo de conflitos entre famílias.

Para corroborar esta ideia, em primeiro lugar, é vital, recordar que segundo uma pesquisa do "jornal notícias" do dia 12 de Outubro de 2011, as mulheres aderem aos serviços dos médicos tradicionais para domar até mesmo matar os seus maridos a fim de herdar os bens materiais que este possue [possui]. Vejamos, por exemplo, que a STV fez uma reportagem sobre uma mulher em contenda com a família do marido, por ter espetado no bolso deste uma agulha tratada pelos serviços destes médicos para matar o esposo. Relativamente a esta opinião é preciso ressaltar e acrescer que muitos homens ao verem que as suas vidas materialmente não correm bem, dirigem-se aos serviços de crenças para se tratar e mandar enloquecer [enlouquecer] um dos membros da linhagem (neto, filho, sobrinho) para que espiritualmente este seja o garante da entrada de moeda (capital) e sucesso no negócio. Por exemplo, tem se travado discução [discussão] nos mercados entre comerciantes e suas famílias ao saberem que este cometeu o acto. Contrariamente, para alguns este pensamento não é comum, pois os serviços dos médicos tradicionais ajudam muitas famílias a sobreviver e resolver os seus problemas quotidianos.

Em suma, os jornais colaboram com os curandeiros para expandir os seus trabalhos. Muitos para enriquecer recorrem à estes serviços prejudicando os outros. Consequentemente, surgem desavencias [desavenças] nas famílias.

\section{Texto C}

Nos dias de hoje é comum notarmos ao longo das vias de acesso da cidade de Maputo escritas nas chapas bem como nos painéis. Trata-se de publicidade dos médicos tradicionais que operam nesse ponto do país, na sua maioria essas informações são enganosas.

Comecemos por dizer que antes de mais é um fenómeno bastante triste o que temos visto nas ruas e espaços públicos, pois os médicos tradicionais aproveitam-se 
Linha D'Água (Online), São Paulo, v. 31 , n. 1, p. 145-170, jan.-abril 2018

do sofrimento das pessoas colocando mensagens enganosas às pessoas. Tratam-se de mensagens que entram em contradição com a ciência porque as doenças cientificamente comprovadas as mensagens alegam que curam as doenças.

Se olharmos numa outra vertente podemos notar que apesar de existirem bons médicos tradicionais que curam realmente algumas doenças que a ciência não consegue, essa estratégia de difundir as informações nos espaços públicos bem como nos órgãos de comunicação social também é uma janela de oportunidade para o aparecimento de falsos médicos tradicionais. Esses falsos médicos que constituem a maioria são os que mais apostam na estratégia de difundir informações enganosas.

$\mathrm{Na}$ minha modesta maneira de ver as coisas, um médico verdadeiramente tradicional não precisa de publicitar os seus serviços, mas sim, pode convencer os seus clientes através do seu trabalho, isto é, provar que cura uma determinada patologia aos seus clientes e não necessariamente divulgar nos órgãos de comunicação.

Também é importante acrescentar que as mensagens postas para o conhecimento de todos têm um cunho comercial enganador: procura escrever nomes de localidades onde potencialmente têm supostamente os grandes médicos tradicionais, alegam que curam doenças como SIDA, CANCRO, aumento da potencia sexual, as diabetes entre outras.

Para além de trazerem mensagens enganadoras também constituem um atraso ao desenvolvimento, pois culturas e tradições às cidades. $\mathrm{O}$ que mais preocupa ainda com esse novo fenómeno é que as autoridades deviam ter uma palávra a dizer. as autoridades competentes deviam criar leis que proíbem a publicação desse tipo de material como forma de estancar o mal.

A publicidade enganosa dos falsos médicos tradicionais não promove o desenvolvimento, cria choques com a ciência, retarda os programas e políticas de consciencialização de pessoas a respeito de epidemias, fumentam abandono no tratamento de doentes nas instituições vocacionadas para lidar com os casos convencionalmente, ou seja, medicina legal; contrariamente com o que oficialmente tem se difundido.

Pode concluir-se que muitas das informações difundidas ainda se baseiam-se em crenças, isto é, não têm uma fundamentação científica. Estes e mais aspectos acima apresentados são elementos mais do que suficientes para afirmar que as 
Linha D'Água (Online), São Paulo, v. 31, n. 1, p. 145-170, jan.-abril 2018

informações dos médicos tradicionais difundidos nos meios de comunicação social sobretudo os jornais e nos espaços públicos da cidade de Maputo são enganosos.

Texto D: Os médicos tradicionais curam doenças crónicas.

Médicos tradicionais são tidos como pessoas que trabalham com raízes medicinais para o curativo de algumas doenças. Estes, por vezes dão os primeiros socorros aos indivíduos doentes que se encontram longe do posto médico (hospital). Na cidade de Maputo foi feito um estudo de modo a se comparar a medicina tradicional. Do estudo feito, detectou-se que a medicina tradicional salva vida de muitas pessoas. Neste caso, conclui-se que esta medicina deveria ser difundida nos jornais e afixada em espaços públicos na cidade de Maputo.

Em primeiro lugar lembrar que o curativo desta medicina, está aberto para todos doentes. Ou seja, é importante que todo aquele que se achar que tem uma doença que o hospital não consegue currar, aproxime-se aos médicos tradicionais. Estes, preparam os curativos tendo em conta que a doença foi dexistida pelos médicos hospitalares. E eles encaram a este tipo de doenca como uma doença que provêm do fetiço.

Para reafirmar a ideia apresenta, as raízes que os médicos tradicionais usam para os curativos das doenças são muito flexíveis. Isto é, estas raízes curam a doença com muita rapidez, deixam o corpo muito leve e, até o doente pode chegar a não acreditar que estava muito grave. Os médicos tradicionais ajudam e facilitam aos médicos hospitalares curativos das doenças.

Contrariamente ao que foi dito, a medicina tradicional não deve ser vista como um refugio às doenças. Por exemplo, existem aquelas pessoas que acreditam mais nesta medicina, ou confiam mais na medicina tradicionais, que em receber os tratamentos hospitalares. Isso leva a uma gravidade e até pode se chagar a morte. Neste caso, o tratamento hospitalar deve ser visto como primordial porque os médicos usam tecnologias aprovadas em todo mundo e com instrumentos que eles usam dão o diagnóstico. Isto é, explicam de forma clara o que o individuo sente e, está explicação não tem sido aleatória como a dos médicos tradicionais. 
Linha D'Água (Online), São Paulo, v. 31 , n. 1, p. 145-170, jan.-abril 2018

Para terminar, embora exista médicos hospitalares, é bom que confiemos também em medicina tradicional. Está medicina por um lado, ajuda aos curativos de doenças obtidas por feitiços. Por outro lado depois dos tratamentos com as raízes o corpos manifesta-se de boas maneiras sem ter mãs reiações dos efectos. 